\title{
A PECULIARIDADE DO MAQUIAVELISMO INGLÊS Das origens ao século XVII *
}

\section{Luís Falcão}

Universidade Federal Fluminense (UFF), Niterói - RJ, Brasil. E-mail: luis.alves.falcao@gmail.com.

DOI: $10.1590 / 339706 / 2018$

Na já hoje clássica obra de Giuliano Procacci, Studii sulla fortuna del Machiavelli, publicada em 1965 e revisada em 1995, o autor justifica o título a partir de uma diferença conceitual nas recepçóes do florentino nos diversos países europeus, tema de seu estudo. De acordo com Procacci (1965, pp. vi-xii), existe uma disjunção entre o que historicamente se entendeu por maquiavelismo e os estudos das obras do próprio secretário desde suas primeiras publicaçôes. O autor se coloca, assim, numa posição de confronto com a percepção de que maquiavelismo e a fortuna de Maquiavel possuem unidade. Por isso,

* Agradeço aos comentários e críticas de Fabrina Magalhães Pinto, Newton Bignotto e dos pareceristas anônimos. Naturalmente, toda a responsabilidade é minha. diz Procacci, seu estudo trata do desenvolvimento das leituras de Maquiavel e não do maquiavelismo ou da reflexão e atitude maquiavélicas. Como quem rejeita os conceitos elaborados previamente, Procacci se impóe o rigor de reler os escritos que tratam de Maquiavel desnudo de maquiavelismo. Continua sua justificativa afirmando que até a Revolução Francesa, pelo menos, a sobreposição dos três nomes maquiavelismo, Razão de Estado e amoralismo - limita os estudos sobre seu emprego.

Outra obra célebre traça o desenvolvimento do maquiavelismo - cunhado como pensamento maquiavélico - com base na junção com o tacitismo, elaborada pelos críticos de Maquiavel. Para Toffanin (1921, pp. 113-114), o cenário protestante do século XVII, principalmente francês, provocou uma bifurcação nas leituras católicas do período anterior que não interpretavam de modo divergente as obras de Tácito e de Aristóteles. Assim, como forma de ataque à intelectualidade católica que se 
debruçava sobre a política (Firpo, 1970, p. 338), um suposto moralismo grego estava sendo lido contrariamente às adaptaçóes que Maquiavel teria feito em Tácito a partir do estudo e da prática da política (Camos, 2008). Maquiavelismo e tacitismo estariam, ambos, em contradição com o aristotelismo e o bem comum, a ciência do bem viver nas cidades (Fontana, 2013, pp. 212-213; Maloy, 2013, p. 7). Com isso, sem dúvida, acrescido o tema da Razão de Estado, a centralidade da crítica passou a residir, pois, na desvinculação entre moral e política (Höpfl, 2004, p. 84). De fato, esforços filológicos foram feitos à época para mostrar a união entre Maquiavel e Tácito, como, por exemplo, nas classificaçóes dos principados (Machiavelli, 1997, vol. 1, p. 119; Tacitus, Anais, IV, cap. 33; Burke, 1991, pp. 486-489; Fontana, 2013, p. 210; Toffanin, 1921, p. 37). ${ }^{1}$

Por este ângulo alternativo àquele elaborado por Procacci é possível também compreender a diferença entre o uso de Maquiavel e o do maquiavelismo (Burke, 1991; Pocock, 2003, p. 351; Toffanin, 1921, p. 126). Acrescenta-se também o fato de que não eram raras as vezes que Maquiavel era citado sob o nome de Tácito, máxima expressão do maquiavelismo (Petrina, 2009b, p. 41). Por fim, o tacitismo sofreu um brutal arrefecimento após a emergência do direito natural e, particularmente, no uso que Hugo Grotius fez dele (Toffanin, 1921, p. 204). Tendo conduzido o maquiavelismo em separado da fortuna de Maquiavel, as leituras de Tácito e da Razáo de Estado, na virada do século XVI para o XVII, consolidariam a ambiguidade no uso dos termos.

A estrutura geral desses estudos pode ser bem compreendida também com base na pesquisa de Victoria Kahn (1994). A autora mostra que a disjunção entre as leituras do Maquiavel maquiavélico, aquele cujas bases se sustentam na eficácia política, e o Maquiavel defensor do bom governo, o crítico das tiranias, reside nas formas em que ele foi empregado contra e a favor do direito divino dos reis e do republicanismo. Além disso, o uso de Maquiavel na literatura inglesa da época, já que também era lido como poeta e dramaturgo, expóe uma divergência para com as interpretaçóes fundamentalmente políticas até a virada do século XVI para o XVII. Seguindo tal embocadura, o presente trabalho destaca as primeiras manifestaçóes dos usos de Maquiavel na Inglaterra e mostra que, nesse momento, havia um Maquiavel despido de maquiavelismo, embora tal leitura não durasse muito mais que algumas décadas, salvo algumas exceçóes que comentaremos. A filosofia política jusnaturalista e contratualista, surgida nesse período, foi a principal responsável por inflar a retórica do anti-maquiavelismo. Em grande medida, esse particularismo inglês se deveu ao ambiente intelectual, político e religioso do reinado Tudor e também à premência dos Discursos sobre a primeira década de Tito Livio (Discorsi) sobre as demais obras, principalmente, $O$ principe.

\section{A fortuna da vida e da obra na Itália}

Originalmente, a resistência conhecida ao secretário florentino não estava relacionada às suas obras, mas sim, à sua biografia. Ainda em sua geração, nos círculos florentinos próximos ao poder da cidade, corriam boatos de que Maquiavel não poderia nem deveria ocupar o cargo na chancelaria, pois seu pai, Bernardo Maquiavel, era um conhecido bastardo, ainda que ele não fosse uma pessoa de renome público como outros membros da chancelaria. Mesmo que o avô de Nicolau tenha, posteriormente ao nascimento, como parece ser verdadeiro, reconhecido Bernardo como seu filho, o boato já estava disseminado demais para revertê-lo, o que projetou a mácula da traição em seu filho. Pelos seus colegas de ofício público era carinhosamente chamado de Machia, pelos arredores do poder, de Bastardo (Firpo, 1970, p. 340). ${ }^{2}$ Assim, quando compôs a Decanalle Prima, após a divulgação do manuscrito, o poema passou a ser identificado como o do autor Bastardo (Firpo, 1970 , p. 344). Era o texto caracterizado pelo autor e não o autor pelo texto, o que não impedia elogios à sua escrita. As passagens, quase anedóticas, de sua biografia são conhecidas como as de um homem constantemente afeito ao deboche, ao humorismo desmesurado, à mentira, à inadimplência e à traição. O interessante aqui é que essa má fama pessoal migrou assim que seus textos literários começaram a ser lidos pelos concidadãos, momento no qual ele passa a ser mais conhecido 
na cidade. Nesse contexto, começou-se a não mais diferenciar o citadino Machia ou Bastardo do escritor de poemas e peças teatrais.

A pessoa e o autor se coadunariam também por um caminho diverso dessa má fama, quando as primeiras obras políticas escritas pelos frequentadores das rodas de conversas intelectuais, os Orti Oricellari, começaram a aparecer. Particularmente no caso do diálogo Della Repubblica, de Antonio Brucioli de 1526, Maquiavel é largamente mobilizado em diversos temas, particularmente naqueles correspondentes à boa ordenação do regime republicano contidos nos Discorsi. Recorre ao realismo político (Procacci, 1965, p. 29) na mesma medida em que reflete sobre a virtù e a fortuna, bem como a necessidade das armas para o autogoverno (Brucioli, 1526, p. 22-25). Uma característica importante é que segue de perto o argumento aristotélico, no qual afirma que o bom governo deve respeitar as leis e ser exercido por cidadãos medianos (Brucioli, 1526, p. 30-31). Talvez a referência cruzada a ambos os autores tenha influenciado a proximidade com a qual seriam lidos posteriormente. Mas o que verdadeiramente nos interessa é que na segunda ediçáo, 1538, Maquiavel surge como um dos interlocutores do diálogo para reproduzir o argumento da igualdade contido no fim do livro I dos Discorsi (Albertini, 1995, p. 74; Dionisotti, 1980, p. 199; Procacci, 1965, p. 31). Mesmo que Brucioli tivesse em mãos um manuscrito do texto, sua inserção após a original publicação de 1532 sugere que era nela onde ele lia os Discorsi. Por outro lado, a primeira ediçẫo de seu livro mantém diversos termos dos Discorsi. Esse é um bom exemplo de unidade entre o Maquiavel companheiro de conversas e o escritor político, ambos, tomados como mestre (Procacci, 1965, p. 33). ${ }^{3}$

Para além da propriedade onde ocorriam as conversas, porém com igual conhecimento de causa, Luigi Guicciardini escreve, nos anos 1530, outro diálogo em que um dos interlocutores também é Maquiavel. Essa é uma passagem interessante da recepção de Maquiavel em Florença, porque o irmáo de Francesco Guicciardini aparentemente assume uma posição semelhante à de Antonio Brucioli, embora distante da vida nos Orti Oricellari (Albertini, 1995, p. 270). No texto, Maquiavel cumpre com a função de antagonista daqueles que defendem suas próprias causas. Por um lado, Maquiavel possui a legitimidade de um estudioso, por outro, suas falas são o exato oposto do que havia escrito em O príncipe e nos Discorsi (Gilbert, 2012, p. 113). Devido à franca oposição de Luigi Guicciardini ao regime republicano, diferentemente do que ocorria com a maioria dos jovens dos Orti Oricella$r i$, e sua tradicional defesa da aristocracia (Albertini, 1995, p. 276), parece interessante que inverta o conteúdo dos textos quando coloca as palavras na boca do autor. Isso aponta para uma ambivalência nascente com relação às divergências entre o homem e o escritor. Em comum nessas defesas, a de Brucioli sincera, a de Guicciardini irônica, havia o fato de esses autores terem conhecido e convivido com Maquiavel funcionário e escritor (Villari, 1927 vol. 2, p. 278-282). ${ }^{4}$

Contudo, as críticas pessoais a Maquiavel não pararam nas ofensas familiares de sua geração. Por exemplo, em 1592, Tommaso Campanella esteve na cidade para consultar suas bibliotecas e, entre os textos estudados, estavam alguns esparsos manuscritos do já falecido secretário. Quase quatro décadas depois, em 1631, Campanella declara que durante sua jornada à Florença dedicou-se com afinco aos textos do "bastardo Machiavello" (Firpo, 1970 , p. 345). Em paralelo com a inescrupulosa fama, as obras começaram a ser divulgadas pelos embaixadores florentinos em outras cidades e países (Anglo, 2005, cap. 1), mesmo assim, na Florença do século XVII, sua pessoa ainda era mais conhecida que suas obras, uma vez que $O$ principe não era lido como um texto original (Firpo, 1970, p. 348). Escritos críticos ao opúsculo não provocavam comoçáo no público leitor, como quando o professor e filósofo Agostinho Nifo publica em 1521 De his quae optimus princibus agenda sunt, texto que refutava paulatinamente $O$ príncipe (Firpo, 1970, p. 349-350; Villari, 1927 vol. 2, p. $170)$. Interessante notar que a fama pessoal se relacionava primeiro aos escritos literários e não às obras políticas, mas com o tempo isso muda (Anglo, 2005, p. 85). "Surgia um Maquiavel estático e escolástico, quase com uma intenção pedante de conduzir uma pesquisa sobre a fenomenologia da tirania” (Firpo, 1970, p. 351). ${ }^{5}$ 
Na sequência do texto de Agostinho Nifo, as consideraçóes a respeito do conteúdo das obras de Maquiavel estavam em voga, embora de modo bem diferente. No caso de Francesco Guicciardini, não se tratava de uma crítica moralista ou de fundo histórico, mas sim de uma discordância quanto à eficácia dos preceitos (Anglo, 2005, p. 89; Firpo, 1970, p. 354). Desse modo, as Considerazioni sui Discorsi del Machiavelli, provavelmente escritas em Roma em 1530, não eram exceção naquela altura: punham Maquiavel como um interlocutor de mesma estatura. Seguindo de modo relativamente paulatino o texto de seu colega, Guicciardini comenta internamente os Discorsi sem alardear a autoria. Mesmo para alguém que publicamente era conhecido pela proximidade com Maquiavel, igualmente funcionário de Florença, e mesmo sem publicar o texto, Guicciardini parecia reticente em chamar o amigo de Machia, de Bastardo ou pelo nome, o que não o impediu que inserisse profundas discordâncias, sem qualquer acusação de amoralismo, ateísmo ou maldade. Pelo contrário, observava em Maquiavel alguém por demais complacente, senão mesmo um defensor, do regime popular (Guicciardini, 1970, p. 611). ${ }^{6}$

Não obstante tal desenvolvimento quanto ao conteúdo, desde os anos de 1540 as obras do secretário passam a ser tomadas em conjunto. Um dos integrantes dos Orti Oricellari, ao lembrar do velho Machia, escreveu certa vez: "todos, por causa de $O$ principe, o odiavam, aos ricos parecia que seu $O$ principe era um documento para ensinar o Duque a lhes roubar tudo, aos pobres a lhes roubar toda a liberdade. Aos chorôes, parecia que era herético, aos bons, desonesto, aos maus, mais mau ainda ou mais valente que eles: de tal modo que todos o odiavam" (Giovan Battista Busini, carta a Benedetto Varchi, Roma 23/1/1549, apud Firpo, 1970, p. 355).

Alguns anos depois, nas Storie fiorentine, Benedetto Varchi parece acompanhar a posição de seu amigo: "A causa do ódio, o qual todos eles atribuíam grandemente [a Maquiavel], era também ele ser licencioso na língua e de vida não muito honesta e do grau do indecoro da obra que compôs e intitulou O principe" (Benedetto Varchi, Storia fiorentia, p. 84, apud Firpo, 1970, p. 357). Tanto na carta quanto no livro, as duas imagens se confun- dem: o autor e a pessoa de Maquiavel, $O$ príncipe e o homem privado (Villari, 1927, vol. 2, p. 173). Mas tal ódio aos aconselhamentos principescos não era novidade na Itália. Portanto, é a partir da última geração que conheceu Maquiavel pessoalmente que as versōes sobre ele se bifurcam, como atestam as reminiscências dessa geração por meio das informaçôes que chegaram a Campanella. Daí em diante, o secretário passa a ser preterido por seus textos.

A historiografia contemporânea já conseguiu estabelecer com um razoável grau de sucesso as divulgaçóes das obras de Maquiavel durante o século XVI. Ainda em sua vida, manuscritos circulavam, principalmente, entre intelectuais de Florença. Devido à manutenção de seu contato com antigos companheiros de chancelaria, resquícios do período que foi funcionário da então república, e ao contato com geraçóes mais novas de embaixadores e servidores públicos, sua obra foi bem divulgada. O convívio com os letrados dos Orti Oricellari, na casa de Bernardo Rucellai, também causou impacto nos primeiros leitores de seu tempo (Albertini, 1995, p. 72).

Também é bastante citado entre os biógrafos e estudiosos o fato de que as primeiras ediçóes impressas foram produzidas poucos anos após sua morte, em 1527. Atualmente, tem-se registro de que a primeira edição surgiu em 1532, com os Discorsi e $O$ principe, embora este, o Decanale prima e, principalmente, $A$ mandrágora já tivessem caído em conhecimento público. A Arte da guerra já havia sido publicada em 1521, embora não se saiba se realmente foi editada. Tendo visto o que ocorreu com a fortuna maquiaveliana nos séculos subsequentes, estranha-se o fato de que a divulgação de suas obras na primeira metade do século XVI não tivesse causado impacto significativo. Nessa esteira, importantes intérpretes de Maquiavel, com especial ênfase em Quentin Skinner (2002), optam por uma leitura que reduz o grau de originalidade comumente atribuído ao florentino, uma vez que, do ponto de vista da tradição dos espelhos medievais, Maquiavel teria pouco inovado. Tal perspectiva justifica o baixo impacto moral que as obras tiveram naquelas décadas, sobretudo, entre os leitores da província itálica, acostumados com os aconselhamentos principescos. 
Uma característica marcante das ediçóes dos Discorsi do período, entre a famosa bladiana de 1532 e a publicada em Veneza em 1550 por Gabriel Giolito de Ferrari, passando pela primeira edição veneziana curada por Comin de Trin, em 1540, é que nenhuma delas traz comentários, prólogos ou introduçóes, seja dos editores, seja de terceiros. O texto, em si mesmo, praticamente não se altera, com raras exceçóes de variaçóes gráficas, o que pode ter contribuído para um estabelecimento rigoroso do texto já nas primeiras décadas.

O choque dos escritos maquiavelianos viria apenas com a expansão editorial, na segunda metade do século XVI, para além das fronteiras itálicas. As primeiras traduçóes aportaram na França e na Espanha nesse período e provocaram incômodo, sobretudo, nos círculos protestantes (Firpo, 1970, p. 367; Praz, 1930, p. 5; Procacci, 1995, p. 213). Entre 1575 e 1655 contam-se 24 ediçóes, dentre as quais dez em francês, oito em latim, quatro em italiano e apenas duas em inglês (Procacci, 1995, p. 133). Apesar de os textos originais terem sido escritos em italiano, a maior parte das ediçóes impressas até esse período, fora da Itália, era em latim e carregava consigo uma estratégia de divulgaçáo, mais marcadamente, nos países católicos (Petrina, 2009a, p. 60). Entretanto, com a maior aceitação dos idiomas nacionais como línguas igualmente eruditas, as traduções ganharam uma importância ímpar. Nelas, e mesmo em italiano, quase sempre encontra-se o subscrito editorial: "escrito em língua vulgar". Percebe-se assim que ao longo desse período o escritor e o personagem de Florença foram progressivamente se afastando um do outro mais uma vez. Isso é particularmente importante na compreensão da peculiaridade inglesa visto que alguns dos pensadores políticos responsáveis pela divulgação de Maquiavel na ilha estavam direta ou indiretamente ligados a reflexóes produzidas na Itália e ao seu próprio mercado editorial (Anglo, 2005, cap. 3; Donaldson, 1988, p. 87). Desse modo, a percepção do homem privado sobreviveu, particularmente no continente, pela força com a qual a sua má fama se disseminava. Não se pode dizer isso do caso inglês, em que suas reflexôes políticas, e sobretudo as versóes republicanas, chegaram bem antes do diabólico bastardo.

\section{A divulgaçáo das obras e a chegada na Inglaterra}

O processo de divulgação no continente europeu se deu através de imigrantes italianos fugindo de perseguiçōes religiosas que levavam os volumes para, primeiramente, França e Espanha (Petrina, 2009a, p. 57) e, depois, Inglaterra e regióes ao norte do Sacro Império Romano Germânico (Petrina, 2009b, p. 8). Esse mapa do itinerário dos textos explica, em parte, as variaçóes nas recepçóes. O próprio fato de os exilados aportarem no estrangeiro sob acusação de irreligiosidade e ateísmo pode ter produzido uma rejeição inicial àquilo que carregavam. Outro fator considerável é a existência de conflitos religiosos entre cristãos e mouros na Espanha e entre católicos e protestantes na França. Em ambos os casos, havia uma percepção comum de que apenas a homogeneidade religiosa seria capaz de aniquilar as contendas. Assim, a chegada de perseguidos católicos pela própria Igreja de Roma não apenas incitaria mais discórdias, como também revelaria alguma fragmentação no seio do Vaticano. A rejeição a eles seria imediata. Com isso, não é difícil entender o asco que os textos maquiavelianos provocaram, por seu conteúdo aterrorizador inflamado por quem os carregava (Procacci, 1995, p. 134).

Apesar da preponderância da divulgação francesa, existem registros de outras formas de comunicação a partir de autores relevantes (Petrina, 2009b, pp. 42-43). De acordo com Praz (1930, p. 9), a primeira vez que o termo machiavellism foi usado na Grã-Bretanha foi por George Buchanan, em 1570 , e, mesmo que não tenha inibido a versão francesa, produziu uma multiplicidade de fontes. ${ }^{7} \mathrm{O}$ fato de que a Inglaterra já havia superado os momentos mais tensos da Reforma Protestante e conquistado uma desenvolvida unidade territorial quando as obras chegaram à ilha britânica limitou a repulsa que se espalhava pelo continente. Assim, a proclamação do Index Librorum Prohibitorum, pelo papa Paulo IV, em 1559, que incluía todos os textos de Maquiavel (Villari, 1927 vol. 2, p. 175), praticamente não surtiu efeito até a época Stuart (Petrina, 2009a, p. 54).

Com relação aos aspectos religiosos, Anglo (2005, pp. 97-102) argumenta que a obra de Ma- 
quiavel já estava sendo usada na Inglaterra nos anos de 1530 a fim de defender a reforma de Henrique VIII contra a autoridade do papa. Certamente, se a hipótese estiver correta, ela se mostra complementar à nossa argumentação, uma vez que não foram os aspectos religiosos os responsáveis pelas críticas a Maquiavel na Inglaterra, como veremos à frente. É verdade também que nas décadas de 1540 e 1550, embora raramente citado, Maquiavel tinha algumas ideias usadas, positivamente, para o ensinamento do jovem Eduardo VI (Idem, pp. 103-109; Raab, 1965, p. 61). Mesmo quando as disputas religiosas, já sob a coroa de Carlos I, produziam adversidades nas publicaçóes, quase sempre envolviam controles políticos e financeiros e carregavam pouco significado moral ou teológico. Outro aspecto importante foi o atraso da chegada das obras, o que, em certo sentido, produziu uma distância temporal maior com relação aos exemplos históricos utilizados e com o próprio personagem Bastardo. Além disso, a coroa britânica esteve menos envolvida nas disputas territoriais da região do que os Estados germânicos, a França e a Espanha. A especificidade inglesa diante dos países continentais proporcionou uma recepção igualmente ímpar. Não obstante esse conjunto de características históricas serem bastante relevantes para o entendimento do Maquiavel inglês, um caso específico chama bastante a atenção. Diferentemente do que ocorreu no continente, na ilha britânica a divulgação dos Discorsi era bem mais consistente do que outras obras, sobretudo $O$ principe. $^{8}$

As primeiras impressóes dos Discorsi publicadas na Inglaterra foram feitas entre os anos de 1584 e 1588, em Londres, por John Wolfe, no original italiano. Os volumes consistiam em uma reediçáo dos Discorsi aos moldes das publicaçóes italianas e deveriam ser acompanhados pelo $O$ principe, em um volume separado, como era comum na Itália. Todavia, as circunstâncias da primeira publicação londrina já apresentavam suas particularidades. A primeira delas é que o editor, John Wolfe, forjou, pela primeira vez na Inglaterra (Donaldson, 1988, p. 90), sua própria identidade e adotou um pseudônimo: Antoniello degli Antonielli. Além disso, alterou a cidade de confecção da brochura: Palermo. Não conseguimos encontrar algum sig- nificado para o nome, é provável que tenha sido mera invenção, mas a cidade escolhida não parece arbitrária (Petrina, 2009a, p. 64; Raab, 1965, p. 52). As publicaçóes maquiavelianas estavam sendo feitas nos principais centros culturais das regiôes centro e norte da Itália, entre elas, Roma, Florença e Veneza. Optar por uma cidade fora do circuito, ao extremo sul do país do autor, bloquearia, simultaneamente, a acusação de que o texto fora confeccionado em plena capital britânica e teria ainda a vantagem de não provocar desconfiança nas cidades do centro-norte da Itália. Além disso, o controle governamental das publicaçóes que tratassem de temas políticos era bastante significativo, sobretudo, para obras estrangeiras (Donaldson, 1988, p. 92). A favor de Wolfe, entretanto, sabe-se que os editores londrinos não desfrutavam de muito reconhecimento por seus serviços profissionais (Procacci, 1995, p. 222), o que, de fato, poderia até mesmo tê-lo encorajado à empreitada.

Em seu prefácio, Wolfe escreve que é a primeira vez que o texto está sendo publicado naquela cidade (Wolfe, 1584 , p. 4), o que contraria o frontispício do livro que informa uma Reimpressáo (Ristampa). Aqui, pode-se aventar a hipótese, Wolfe pode ter cometido um equívoco ou deixado uma pista sutil aos mais atentos da verdadeira origem do editor e da cidade. Acrescenta-se ainda o fato de o texto estar na língua original e também não chamar a atenção a diferença idiomática, mesmo aos que estivessem cientes das variaçóes entre o toscano e os dialetos ao sul, alertadas pelo próprio Wolfe (1584, p. 4) que, segundo o próprio, tratou de corrigir a grafia. De fato, estes são elementos que possibilitam uma indicação de quão consciente Wolfe estava da responsabilidade de uma publicação como aquela, o que sugere algum conhecimento, entre os leitores, da má fama do secretário.

O frontispício da obra traz escrito: "I Discorsi di Nicolo Machiavelli, sopra la prima deca di Tito Livio. Con due tavole, l'una de capitoli, e l'altra delle cose principali: e con le stesse parole di Tito Liuio a luoghi loro, ridotte nella vulgar Lingua. Nouellamente emmendati, e con somma cura ristampati. Il vostro malignare non giova nula. In Palermo. Appresso gli heredi d'Antoniello degli Antonielli a XXVIII di genaio 1584 ".? 
Alguns termos parecem significativos se contrastados com as ediçóes italianas. A primeira coisa de destaque é um preciosismo editorial de Wolfe, a inclusão de um índice, provavelmente elaborado pelo próprio, basicamente dos nomes de lugares e personagens, já nas primeiras páginas, o que não ocorria nas ediçóes continentais. Inclui-se também o já comum destaque para a língua vulgar usada na tradução do latim das passagens de Tito Lívio. A necessidade de dizer que o texto foi reimpresso com sumo cuidado parece querer alertar o leitor que já haveria uma edição feita pelo Antoniello degli Antonielli publicada em Palermo, o que eximiria John Wolfe e Londres de qualquer responsabilidade pela confecção da obra, mesmo que pudesse ser acusado de ela estar sob seu resguardo. Ao lado de uma imagem de uma palmeira florescente, lê-se: "O vosso mal não auxilia nada” (tradução livre). Wolfe poderia aqui estar sugerindo - utilizando uma palavra comum a Maquiavel, giovare, que em italiano também pode significar florescimento - certa defesa do autor: "O vosso mal em nada floresce". Se for esse segundo caso, o locutor da sentença seria o mesmo que o do prefácio, dirigindo-se a seus detratores, defendendo Maquiavel (Donaldson, 1988, p. 94, n. 24).

Apesar de todas essas particularidades, o que chama realmente a atenção é o prefácio ("Lo stampatore al benigno lettore") que John Wolfe escreve para a publicação em aberta e franca defesa de Maquiavel. ${ }^{10} \mathrm{O}$ texto traz uma justificativa da necessidade da publicação, pois "hoje mais que nunca nós acreditamos nos homens ou em seus escritos, segundo o bom e o reto juízo de quem os ouve e que sabem quem estimamos homem verdadeiro e bom" (Wolfe, 1584, p. 2, tradução livre). O editor não deixa dúvidas de que a publicação poderia causar incômodos e, por isso, busca argumentar contrariamente à importância da autoridade, como ocorrera ainda em vida de Maquiavel. A estima que se tem dos homens produz uma avaliação prévia de seus escritos, argumenta. Wolfe comporta-se diante do leitor como quem clama por uma leitura despida dos preconceitos, porque Maquiavel não era considerado como parte daqueles homens estimados, e disso a herança florentina é testemunha.

Mas parece que Wolfe destina seu texto a um público mais amplo que os restritos círculos ingle- ses interessados em Maquiavel, pois ao se preocupar com a má fama do florentino, o editor acaba por considerar o conhecimento público do autor e defende que sua vida pessoal seja desconsiderada durante a leitura. Alternativamente ao argumento de autoridade, Wolfe prega que o texto seja julgado por si mesmo, assim, o leitor deve "tratar de ver se a verdade nos seja dita" (Idem, ibidem, tradução livre), mesmo porque Maquiavel não cometeu qualquer ofensa contra quem o lê. Daí em diante, tece os mais altos elogios ao "literato", "muito sábio" e "muito profundo [...] nas questóes políticas" (Idem, pp. 2-3, tradução livre). Segue a apresentação com a diferença entre um príncipe justo e um tirano (tema fundamental do pensamento político inglês do século seguinte), o governo dos "muitos bons" e dos "poucos maus". Contudo, não deixa de reconhecer a má fama do secretário: "Mas é bem verdade que se ouve que havia a audácia de se escrever contra ele" (Idem, p. 3, tradução livre). Depois de confessar ter lido os críticos, rebate dizendo que não são convincentes. Explica, então, suas fontes para o estabelecimento do texto, as ediçóes venezianas de 1546 e 1550 , e caminha para o encerramento justificando supostos erros nas citaçóes de Tito Lívio, equívocos perfeitamente compreensíveis, porque "existindo em Aristóteles e em outros grandes escritores erros semelhantes de memória" (Idem, p. 4, tradução livre), não se deveria acusar Maquiavel por tal equívoco. Aqui, diferentemente do que ocorreria décadas depois, Aristóteles é uma autoridade respeitável quando comparada a Maquiavel. Wolfe termina, enfim, prometendo a publicação de História de Florença, que ocorreria apenas em 1587, e uma nova edição da Arte da guerra, já publicada na Inglaterra em 1562 (Procacci, 1995, pp. 213-214).

John Wolfe é uma figura central na interpretação de Maquiavel como um pensador do bom governo e o motivo de ter escolhido Londres para a empreitada ainda é tema de controvérsia. É seguro, porém, que ele viveu alguns anos em Florença, provavelmente entre 1569 e 1576 (Donaldson, 1988, p. 91), onde travou contato não apenas com as obras, mas também com o personagem, como vimos, ainda em voga no período. Lá trabalhou com Gabriel Giolito de Ferrari, o mesmo que publicou os Discorsi em 1550. A edição de Ferrari segue os padróes ita- 
lianos: escrito em língua vulgar, com tábua dos capítulos, corrigida e, apesar de não ter prefácio, era semelhante ao que faria Wolfe mais tarde. Todavia, uma característica chama a atenção: ambas as ediçôes trazem imagens de capa elaboradas de figuras que fazem alusão à repercussão do texto, diferentemente do que ocorrera com a conhecida edição veneziana de 1540, que traz uma imagem de Maquiavel. Na capa de Ferrari, tem-se dois demônios sentados levemente sorrindo em sinal de escárnio; na de Wolfe, como vimos, representa-se uma árvore frondosa. Parece seguro afirmar, sabendo que trabalharam juntos, que a ideia de uma imagem que represente o conhecimento comum do autor era original de Ferrari e isso foi seguido por Wolfe. O que este faz, porém, é transformar a figura demoníaca na crítica ao mal atribuído a Maquiavel.

Sabe-se que Wolfe era o principal editor das obras do jurista italiano Alberico Gentili naquela mesma década. Em livro publicado originalmente em Londres em 1585, escrevia Gentili, comentando $O$ príncipe, que Maquiavel "era um apologista da democracia e seu campeão mais espirituoso. [...] O propósito do mais sagaz dos homens era instruir as nações sob o pretexto de instruir os príncipes" (Gentili, 1924, p. 156). ${ }^{11}$ Estavam ambos, assim, alinhados com uma interpretação bem heterodoxa de Maquiavel, mesmo para os parâmetros ingleses. O sucesso das obras de Gentili e a repercussão das publicaçóes do secretário de Florença eram simultaneamente causa e efeito de um Maquiavel desconhecido no continente e, agora, até $O$ príncipe ganhava uma defesa explícita.

Trabalhando juntamente com John Wolfe, Petruccio Ulbaldini, que assina com o pseudônimo de John Levvet, escreveu o prefácio para a reedição em 1588 e para a pioneira tradução de 1599 , de sua responsabilidade. ${ }^{12}$ É plausível que esse seja o primeiro texto publicado na Inglaterra e em inglês que trata explicitamente dos Discorsi (Orsini, 1937, p. 21) ${ }^{13}$ e não é pouco significativo que eles sejam tratados com respeito e dignidade. ${ }^{14}$ No seu prefácio, o tradutor justifica a necessidade da ediçáo através de uma explícita defesa do republicanismo, mesmo quando reconhece a associação de seu nome ao profano e irreligioso. "A verdade é que ele era um estadista, o principal membro da república de Florença e secre- tário da mesma, e é sobre o governo de uma república que ele discursa nesse tratado" (Ulbaldini, 1937, p. 43, tradução livre). Petruccio Ulbaldini acrescenta à defesa de Wolfe não apenas o republicanismo, mas, sobretudo, o realismo político, quando afirma que não escreve para desculpar Maquiavel por seus erros, mas para alertar o leitor de que ele não precisa acreditar no secretário, porém, deve lê-lo sob a perspectiva do conhecimento (knowledge), o que não era exatamente uma novidade, uma vez que manuscritos de $O$ príncipe na Inglaterra já continham uma perspectiva cientificista do autor (Petrina, 2009a, p. 69). Depois de comentar a tradução, afirma que Maquiavel "objetiva o bom governo da república" (Ulbaldini, 1937 , p. 45, tradução livre). Entretanto, o tom da epístola à segunda edição em inglês, sem data, é claramente defensivo e cauteloso, como quem deseja se eximir da responsabilidade pelo que está escrito, como se tivesse sofrido as mais duras críticas pela publicação de 1599.

Orsini (1937, p. 21-24) argumenta que a perspectiva republicana do trato de Petruccio Ulbaldini para com Maquiavel justificava-se pelos conflitos religiosos em curso no continente. $\mathrm{O}$ que era negativo na França, a leitura amoral e irreligiosa, ganhou um contorno positivo, ou seja, a separação entre política e religião atribuída a Maquiavel por Petruccio Ulbaldini seria a única forma de evitar a reproduçâo da Noite de São Bartolomeu (Kahn, 1994, p. 124; Procacci, 1995, p. 221). O contraste com a França é evidente. Após o massacre, ocorrido em 1572, ele foi atribuído à leitura de Maquiavel, particularmente, ao tema do conflito nos Discorsi (Villari, 1927 vol. 2, p. 181). ${ }^{15}$ Todavia, um outro Maquiavel se desenhava na Inglaterra através da laicidade como instrumento para deter os massacres religiosos. $\mathrm{Na}$ proximidade com o Estado laico encontrava-se o republicanismo, defendia Ulbaldini. Desenvolver-se-ia na Inglaterra elisabetana a noção de que tolerância religiosa e o Estado laico não eram apenas termos conciliáveis, mas interdependentes - e nesse sentido a obra de Maquiavel teve sua importância (Raab, 1965, p. 61). Assim, a observação inglesa dos acontecimentos no continente projetou, desde o início, o trato da política sob a perspectiva do realismo maquiaveliano. Em vez de julgamentos valorativos e morais, Maquiavel estava sendo lido como um autor que descreve a po- 
lítica e não como um teórico que produzia prognósticos e doutrinas.

O percurso das ediçóes contribui significativamente para o entendimento da particularidade inglesa. A chegada dos Discorsi em ediçóes cuidadosamente elaboradas blindou parcialmente a leitura principesca ou mesmo tirânica do secretário. Esse processo teve rebatimentos importantes no pensamento político inglês subsequente. Nessa esteira, trataremos de alguns casos a título de exemplo e justificação.

\section{O primeiro maquiavelismo inglês e sua difusáo}

Ainda nos primeiros anos do século XVII, quando as versóes de Maquiavel eram majoritariamente de segunda mão (Petrina, 2009a, p. 51), o ponto alto dessa divulgação entre os letrados foi responsabilidade de Francis Bacon (Procacci, 1995, p. 234). Se o ambiente em torno do qual se lia Maquiavel já era propício para a aceitação do realismo (Raab, 1965, p. 24), com Bacon, a fortuna de Maquiavel na Inglaterra sofre uma inflexão e a política passa a ser vista de modo autônomo da moral (Orsini, 1936, pp. 24-26; Skinner, 1998, p. 10). Bacon parte de exemplos pontuais de acontecimentos históricos para, em seguida, retirar conclusóes generalistas (Bacon, 1998, p. 230; Orsini, 1937, p. 42). Além dessa perspectiva, insere temas militares afeitos a Maquiavel: a defesa da expansão territorial, o uso da infantaria e afirma que "[n] either is money the sinews of war" (Bacon, 1955, p. 79), numa tradução, sem citar, dos Discorsi: "I dannari non sono il nervo della guerra” (Machiavelli, 1997, vol. 1, p. 350). ${ }^{16}$ De fato, não só nos Ensaios, mas outras obras também estão repletas de referências diretas e indiretas a "um dos doutores da Itália, Nicolau Maquiavel” (Bacon, 1955, p. 35).

Após os escritos de Bacon, Marchamont Nedham foi o inglês que mais contribuiu para a divulgação das ideias de Maquiavel (Raab, 1965, p. 159; Rahe, 2008, p. 183; Sullivan, 2004, p. 115). ${ }^{17}$ "Para Nedham, então, Maquiavel deve ser usado de muitas formas" (Raab, 1965, p. 161), por isso, destacaremos o ponto que será importante para este estudo, seu fundamento republicano. $\mathrm{O}$ vocabulá- rio de Nedham é totalmente centrado no de Maquiavel: virtue, fortune, humors, tumult, grandee, reputation, laws and liberty etc., além do emprego dos mesmos exemplos republicanos (Foxley, 2013, p. 50) e com o auxílio de Francesco Guicciardini. Mas são os fundamentos teóricos retirados de citações dos Discorsi os mais interessantes. Para Nedham, o povo é o melhor guardião da liberdade, que, por sinal, se opóe à monarquia (Pocock, 2003, p. 382). A melhor forma de manter a liberdade é através do governo misto, que leva à expansão e limita o andamento dos ciclos de governo (Nedham, 2003, pp. 15, 35, 64 e 68). Já em The case of the commonwealth of England, stated, Nedham tratava do florentino com respeito e admiração. $\mathrm{Na}$ ocasião, concedia maiores destaques ao tema das eleiçóes e, sobretudo, ancorava-se nos exemplos históricos. Parecia querer justificar a recente execuçáo do rei pelo sexto capítulo de $O$ príncipe (Nedham, 1968, p. 35). Destaca-se ainda sua preocupação com jure divino que, segundo ele (Idem, p. 88), ameaçava a estabilidade inglesa.

$\mathrm{Na}$ mesma geração, James Harrington, o mais importante maquiaveliano inglês, acrescenta à defesa da república a crítica ao jusnaturalismo de matriz hobbesiana (Harrington, 1977, vol. 1, pp. 174179). O uso de Maquiavel por Harrington é demasiadamente divulgado para que precisemos sumarizar aqui, então destacamos somente os termos de continuidade. Como Bacon, Harrington reafirma a necessidade dos cidadáos armados em infantaria; como Nedham, defende a república popular, o governo misto, a virtude e a liberdade. Fitando erigir uma república imortal (immortal commonwealth), Harrington se sustenta nos exemplos históricos, antigos e modernos, com um sofisticado sistema institucional no qual todas as instâncias são eletivas. Diferentemente do que estava sendo feito no último meio século, como veremos à frente, Harrington emprega Aristóteles em paralelo com renascentistas italianos, dos quais se destacam também Donato Giannotti e Gasparo Contarini para tratar da sereníssima república de Veneza e usa a autoridade de historiador de Guicciardini. Com estas referências renascentistas, ataca diretamente o pensamento absolutista de Bodin, Filmer e Hobbes. Em um misto de descrição e normatividade, o autor de The com- 
monwealth of Oceana assenta as bases maquiavelianas fundamentais para o republicanismo inglês.

Henry Neville, escrevendo depois da restauração, segue de perto o argumento harringtoniano de balance, isto é, de que a forma de governo depende da distribuição de propriedade no país (Pocock, 2003, p. 406; Neville, 1969, pp. 68, 100 e 132). Além disso, se utiliza diversas vezes do "divine $\mathrm{Ma}$ chiavel' (Idem, pp. 81 e 126), em clara ironia com alguém conhecido como o demônio, para defender seu programa republicano: o governo misto, império das leis e a liberdade. Porém, uma vez derrotada a república inglesa, a forma institucional republicana já não era mais viável; cabia somente a redução do poder do rei (Arienzo, 2009, p. 212; Sullivan, 2004, p. 20). Havia em comum nessas leituras de Maquiavel os seus fundamentos republicanos desenvolvidos nos Discorsi, marcante característica das primeiras ediçóes inglesas. Para os propósitos deste estudo, uma carta escrita por Neville e ironicamente atribuída por ele mesmo a Maquiavel na edição de suas obras é de suma importância: "Meus acusadores [...] me fazem primeiramente exortar e ensinar os súditos a se livrarem de seus príncipes e depois de instruir monarcas como escravizá-los e oprimi-los" (Neville, 1680, p. 28, tradução livre). A passagem é praticamente uma reprodução literal da interpretação de Gentili, corroborando com a presença das ediçóes de Wolfe um século depois, em conformidade com a fama florentina de Maquiavel.

Em paralelo a essa sequência elogiosa do secretário florentino, crescia o tema do absolutismo, do jusnaturalismo e das contendas religiosas. $\mathrm{O}$ fato de a igreja anglicana ter surgido e se desenvolvido intrinsecamente à coroa britânica produziu efeitos interessantes. Se, de um lado, a proximidade teológica e institucional da igreja fundada por Henrique VIII com o Vaticano ajudava a neutralizar os fundamentos das críticas advindas dos protestantes (Maloy, 2013, p. 3; Pocock, 2003, p. 350), de outro, gerava reaçóes desmedidas à intelectualidade católica predominante. A figura de Ignácio de Loyola passava a ser associada a Maquiavel entre os letrados protestantes, mas não apenas entre eles: "No começo do século XVII, o maquiavelismo jesuíta era já um clichê entre os inimigos dessa Sociedade, católicos e protestantes" (Höpfl, 2004, p. 85). Argumentava-se que a Companhia de Jesus deixara para trás a dimensão espiritual como responsabilidade de sacerdotes cristãos e atinha-se, desde então, à política mundana (Praz, 1930, pp. 43-44). Eram todos cunhados, Maquiavel e jesuítas, de polypragmatic, isto é, aquele responsável por, voluntariamente, disseminar a cizânia entre os que compartilham de mesmas crenças (Praz, 1930, p. 45; Raab, 1965, 62; Toffanin, 1921, p. 94). Interessante que Maquiavel, tido até a década de 1650 como um precursor do pensamento jesuíta (Praz, 1930, pp. 47-49), tenha sido bloqueado das críticas direcionadas aos próprios jesuítas. Não é sem sentido observar que essa unidade resistirá no pensamento político inglês pelo menos até os anos de 1680 (Raab, 1965, p. 230). Tal unidade interpretativa, bastante forçada, acabou por deixar de lado o próprio precursor para atacar aqueles que estavam mais em voga. Com isso, mais por negligência do que por falta de vontade, Maquiavel foi menos atacado na Inglaterra. $\mathrm{Na}$ verdade, os primórdios do antimaquiavelismo inglês remontam às obras críticas desenvolvidas no continente.

$\mathrm{O}$ antimaquiavelismo, que surgiu na França de fins do século XVI e se espalhou pelo continente na primeira metade do século seguinte, unifica-se pela interpretação da obra de Maquiavel como criadora da Razão de Estado (Orsini, 1937, p. 26; Villari, 1927, vol. 2, p. 176). Devido à ambivalência das leituras religiosas, a perspectiva da Razão de Estado esteve mais presente do que o próprio ateísmo (Burke, 1991, p. 483; Procacci, 1995, p. 139). Um exemplo claro disso é a acusação que panfletários protestantes, dos dois lados do canal da Mancha, faziam aos jesuítas. O ápice desse conflito intelectual entre aqueles que disputavam conceitos religiosos se deu com Inocent Gentillet. ${ }^{18}$

Do ponto de vista da reflexão religiosa, é plausível que se estabeleça uma classificação que não necessariamente se enquadre em moldes nacionais. Dito de outro modo, são dois processos distintos, aquele que promoveu a divulgação das obras de Maquiavel entre os países e o que produziu uma preocupação político-religiosa com seus escritos. Se, de um lado, a Inglaterra tinha suas particularidades na recepção de Maquiavel, de outro, seus pensadores político-religiosos mais fervorosos não encontravam dificulda- 
des morais nos textos do florentino, apesar de, via de regra, negligenciarem seu nome. $\mathrm{O}$ caso do defensor do direito divino dos reis Robert Filmer é emblemático. Objetivando atacar jesuítas como Roberto Belarmino e Francisco Suárez, Filmer (1991, pp. 1116) emprega importantes referências de Maquiavel quanto ao governo principesco associado à Razão de Estado. É irônico que o próprio pensamento jesuíta aplicava máximas próximas à Razão de Estado associadas a Maquiavel (Höpfl, 2004, pp. 100-103). A recusa de temas fortemente vinculados ao maquiavelismo, como o do conflito, também ocorre em ambos os lados da querela (Barducci, 2009, p. 187). Assim, não é Maquiavel que os diferencia (Arienzo, 2009, p. 239, n. 54; Kahn, 1994, p. 90), mas ele não deixa de ser o melhor dos pretextos para amaldiçoar o inimigo.

Desse modo, nas primeiras décadas do século XVII, o vínculo que Maquiavel tinha com a Razão de Estado deve-se não apenas aos teóricos dessa reflexão política (Raab, 1965, p. 122), mas também à leitura aristotelizante, sobretudo de $O$ príncipe, a partir do quinto livro da Política, comumente associada aos pensadores católicos (Burke, 1991, p. 484; Villari, 1927, vol. 2, p. 152). Por outro lado, confrontava-se Maquiavel igualmente com Jean Bodin, em virtude da política como observação e experiência (Procacci, 1995, pp. 150-152). Com relação a este último, inclusive, existem pelo menos três ediçóes conjuntas na primeira metade do século XVII, colocando ambos em pé de igualdade, publicadas em 1600, 1643 e 1648. Essa tríade Maquiavel, Aristóteles e Bodin - não era estranha a autores leigos, porém, destacava-se com mais clareza entre os adeptos dos fundamentos religiosos na política (Kahn, 1994, p. 95; Toffanin, 1921, p. 95; Tuck, 1979, p. 44). Novamente, tanto para os jesuítas quanto para autores como Filmer, à unidade da tríade incluía-se ainda o manual para governantes e o tema da soberania, uma vez que eram igualmente lidos como autores mundanos. Não estava em questão a autoridade intelectual dos três pensadores, mas o uso que se fazia deles.

As obras de Maquiavel divulgadas ainda no século XVI se relacionavam com outros autores de modo muito difuso. Suas peças teatrais e seus textos históricos quase sempre eram transmitidos junta- mente com escritores e poetas humanistas e, nesse sentido, Maquiavel não estava sendo lido como um autor fundamentalmente político até Wolfe (Kahn, 1994, pp. 96-106; Petrina, 2009b, p. 12). A erudição com a qual ele era tratado fez com que suas obras fossem mais comumente lidas no original italiano, mesmo que existissem raros e disputados manuscritos em inglês (Orsini, 1937, pp. 4-5; Procacci, 1995, p. 214). Outra fonte inglesa era por vias secundárias, através de edições latinas oriundas, sobretudo, da França. Além disso, a preocupação com os jesuítas, que eram os principais representantes do pensamento político católico do período, também produziu uma leitura bastante específica (Petrina, 2009a, 52). Em nenhuma dessas perspectivas havia motivos que justificassem qualquer ataque furibundo ao secretário de Florença.

$\mathrm{Na}$ verdade, a rejeição às teses maquiavelianas se deu menos pela religiosidade do que pelas teorias do direito natural laico. Mais fortemente do que no continente, na Inglaterra, havia a percepção de que a reflexão de Maquiavel colocava a política, não necessariamente em padróes irreligiosos, mas, com certeza, desvinculada de critérios transcendentes ao homem e, por isso, despidos de moralidade. $\mathrm{O}$ que provocara indignação na França ganhou um contorno mais sutil na Inglaterra. Não era mais o amoralismo irreligioso o problema, mas a ausência de regras estabelecidas pela natureza que pudessem orientar a caminhada do ser humano na Terra (Pocock, 2003, p. 370; Tuck, 1979, p. 128; Zuckert, 1994, p. 122). A ausência de parâmetros preestabelecidos para a política - e qualquer outra forma de convívio humano - se mostrava insuportável àqueles que penavam por parametrizar a política, a começar por Thomas Hobbes e John Locke, que lhe negam qualquer legado (Raab, 1965, p. 194; Rahe, 2008, p. 263; Smith, 2006, p. 36; Sullivan, 2004 , p. 80 , n. 1). No caso de John Milton, sua defesa da liberdade, do governo das leis e sua crítica à monarquia, não implicam qualquer uso significativo do florentino; assentam-se, pois, no direito natural de autodeterminação dos povos (Raab, 1965, p. 176; Rahe, 2008, p. 104; Skinner, 1998, p. 19). O silêncio quase absoluto de Milton diante de Maquiavel, visto que em suas principais obras o florentino sequer é citado, é bastante significativo 
porquanto se saiba que ele se dedicou aos Discorsi por alguns anos (Sullivan, 2004, p. 122, n. 25). ${ }^{19}$ Não é improvável que a moralidade de seu jusnaturalismo o tenha contido quanto às referências e o tornado comedido nos usos do secretário.

De fato, as próprias premissas do direito natural recusam, em si mesmas, o realismo, para não falar no uso exemplar da história e na incapacidade humana de obter certezas políticas. Maquiavelismo e jusnaturalismo são modos bastante divergentes de se pensar a política e quando aproximados revelam suas contradições (Arienzo, 2009, p. 234; Barducci, 2013, p. 161; Zuckert, 1994, p. 127). Duas são as perspectivas pelas quais os autores jusnaturalistas tratavam Maquiavel: o esforço para apresentar uma negligência ou a ambiguidade. Partícipe desta segunda corrente, encontra-se Algernon Sidney. Assim como a recepção de Maquiavel na Inglaterra foi absolutamente peculiar e pouco afeita aos temas religiosos, o direito natural, por outro lado, acabou por ocupar o papel crítico desempenhado pelos religiosos continentais, com exceção, em parte, dos jesuítas. Sidney, usando jesuítas e Milton a fim de criticar Filmer e Hobbes, explicita toda sua dívida para com Maquiavel. Em seu livro homônimo ao do florentino e igualmente dividido em três partes, Discourses concerning government, defende o governo das leis e misto, bem como critica a hereditariedade e as formas monárquicas no mesmo compasso em que opóe virtude e fortuna. Diferencia, como fizera Wolfe, rei de tirano (Sidney, 1990, p. 283) e cita Maquiavel inúmeras vezes como autoridade histórica e política, às vezes, ao lado de Guicciardini (cf. Sidney, 1990, p. 521 e 545). Não deixa também de relacionar a expansão dos Estados à sua liberdade e à cidadania armada. Mas não se cala quanto ao direito de resistência dos povos, à lei da natureza e ao direito natural. Já em Court maxims, obra anterior, aparece a crítica: a maldade, a fraude, a perfídia e a crueldade de Maquiavel se relacionam com a de Tácito (Sidney, 1996, p. 24 e 83). Sidney é um caso raro de latente ambiguidade entre maquiavelismo e jusnaturalismo naquele conturbado ambiente de incertezas durante o reinado de Carlos II do qual é necessário um estudo à parte para compreendê-lo.

Até meados do século XVII observou-se uma significativa expansão das leituras de escritores italianos, do humanismo àquele momento, como atestam Bacon, Nedham e Harrington. Era comum, seguindo exemplo de Veneza, compilações de textos que envolvessem temáticas assemelhadas, entre as quais conformavam escritos teatrais, poéticos, históricos e políticos. Uma referência importante é a edição dos Discorsi, publicada por Marco Ginammi, em Veneza no ano de 1630, que teve espaço entre letrados ingleses e náo é improvável que tenha sido a edição usada por James Harrington (Melamed, 1983). A letra maquiaveliana não sofre qualquer alteração das ediçóes anteriores, apenas não traz a dedicatória e nenhum dos dois prólogos e foi publicada no mesmo volume que os Discorsi politici de Paolo Paruta, igualmente na íntegra. Porém, uma coisa chama a atenção: o nome do autor dos Discorsi aparece como uma compilação de "grandes escritores" (grandissimi scrittori) feita por Amadio Niecollvcci, claro anagrama de Niccolo Maciaveli.

$\mathrm{Na}$ verdade, cabe destacar, a prática de ocultar o autor estava mais disseminada na Inglaterra, desde a última década do século anterior, incluindo um manuscrito de $O$ príncipe, traduzido praticamente na íntegra para o inglês na Universidade de Oxford (Petrina, 2009a, p. 71). Ao contrário do que ocorreu com as ediçóes londrinas de 1584 e 1599, quando os editores esconderam seus próprios nomes, aqui foi o autor que teve sua identidade vedada ao leitor. Isso se torna significativo na medida em que se compreende que em pouco mais de três décadas ocorre uma inversão; em ambos os casos, o claro objetivo é de precaver-se contra possíveis ataques. A opção de 1630 reforça a ideia de que a rejeição a Maquiavel já estava mais disseminada do que em 1584 e $1599 .{ }^{20}$

Naquela altura, seus críticos costumavam ler com cautela suas palavras, de modo a demonstrar sua impiedade. Diferentemente do uso instrumental que se fazia de Maquiavel, justamente pela sua má fama, em paralelo, ela se converte em realismo. Maquiavel, então, passa a ser lido como um autor político stricto sensu. Da década de 1570 até a de 1660, o maquiavelismo contido em $O$ príncipe havia decantado em Razão de Estado, ateísmo, imoralidade para parte significativa do pensamento político inglês (Barducci, 2013, p. 160; Harding, 
1994, p. 59; Kahn, 1994, p. 134; Maloy, 2013, p. 6; Pocock, 2003, p. 355) e o próprio uso do termo definia aquele que se dedica à atividade: politician (Höpfl, 2004, p. 105; Praz, 1930, p. 20; Procacci, 1995, p. 224). ${ }^{21}$ Bem verdade que nem todos aqueles que se referiam a Maquiavel sustentavam os mesmos assuntos, como vimos, por exemplo, com Bacon, Nedham e Harrington. E não é coincidência que nesse mesmo período são desenvolvidas na Inglaterra as bases fundamentais do jusnaturalismo ocidental. ${ }^{22}$ Mas, ainda assim, a associação constante entre Maquiavel, maquiavélico, maquiavelismo etc. com políticos, tanto os que refletem quanto os que atuam, era corrente (Höpfl, 2004, p. 99). De fato, a unidade predominante, não obstante as peculiaridades do início da recepçáo inglesa, era uma forma crítica, senão ofensiva, de se acusar alguém de ardiloso, ateu, amoral, em suma, de político. Em 1656, porém, ocorre uma exceção: "Maquiavel, o único político dos tempos modernos”, escreve Harrington (1977, vol. 1, p. 162, tradução livre) contra a corrente. Não por utilizar ambos os termos em conjunto - Maquiavel e político -, mas por fazê-lo de modo positivo e elogioso: o Maquiavel e o político. O uso de Maquiavel associado ao republicanismo é um exemplo claro da transmissão das primeiras publicaçóes, particularmente, dos Discorsi (Arienzo, 2009, p. 210; Skinner, 1998, p. 26). Os que se opunham à república, também se opunham a Maquiavel e, historicamente, com a derrota do projeto republicano, finda também o elogio ao florentino e inicia-se a hegemonia do pensamento jusnaturalista de base monarquista e liberal.

\section{Notas}

1 Na Inglaterra, a imbricação com Tácito ainda pode ser encontrada, devidamente calibrada pelos Mistérios de Estado (Arcana Imperii) em Marchamont Nedham (2003, p. 68), que exerceu influência em pensadores políticos da segunda metade do século XVII.

2 De fato, era um lugar comum entre os florentinos esse tipo de zombaria entre amigos. Mesmo que o adjetivo prejudicasse sua imagem, não era exatamente uma coisa estranha ao espírito cômico florentino, de modo que o apelido pode ser apenas uma brincadeira.
3 Sobre a recepção de Maquiavel no pensamento de Brucioli e no contexto daqueles jovens, ver Bignotto (no prelo). Para uma interpretação alternativa, ver Dionisotti (1980, pp. 201-203).

4 A reciprocidade de Maquiavel com Luigi Guicciardini é a dedicatória do Dell'ambizioone (Machiavelli, 1997, vol. 3, pp. 43-47) conhecida de seus amigos. Ver Villari (1927, vol. 2, p. 586). Guicciardini critica Maquiavel por suas posições republicanas.

5 Todas as traduçôes de citações de obras em língua estrangeira são do autor do artigo.

6 Guicciardini seria lido na Inglaterra do século seguinte bem próximo de Maquiavel, o que torna as discrepâncias entre ambos ainda mais interessantes.

7 Sobre a origem do termo machiavelisme, ver Anglo (2005, p. 3), que a atribui ao ano de 1611, na França.

8 Desde 1544 havia uma edição dos Discorsi em francês, publicada e traduzida por Jacques Gohory em Paris, reeditada em 1548 (Camos, 2008). Ainda assim, seu acesso era bem restrito, ao contrário do que ocorria com O príncipe (Procacci, 1965, p. 109).

9 Os Discursos de Nicolau Maquiavel sobre a primeira década de Tito Lívio nos seus termos, reproduzidos em língua vulgar. Novamente alterados e com sumo cuidado reimpressos. $\mathrm{O}$ vosso mal não auxilia nada. Em Palermo. Impresso por Antoniello degli Antonielli em 28 de janeiro de 1584.

10 Alguns intérpretes questionam a veracidade da assinatura contida na estampa. Sugere-se que o texto poderia ter sido escrito por Giacomo Castelvetro ou mesmo Alberico Gentili (Petrina, 2009b, pp. 26-27).

11 Essa afirmativa remete à de Giovan Battista Busini, acima referida, de que $O$ príncipe era um livro de ensinamentos.

12 A primeira versão impressa de $O$ príncipe em inglês é de 1640 , sob responsabilidade e tradução de William Dacres, que publicou os Discorsi quatro anos antes (Kahn, 1994, p. 125; Petrina, 2009b, p. xii).

13 Repare-se ainda que Ulbaldini, como Wolfe, utiliza um pseudônimo inglês que esconde o seu verdadeiro nome italiano.

14 Raab (1965, p. 53) ignora o caráter pioneiro dessa edição, apesar de reconhecer sua existência (Raab, 1965, p. 65).

15 Evidência disso é o tratado monarcômaco Vindiciae contra Tyrannos, publicado em francês em 1579: "foi através do estudo dos livros de Maquiavel" (Brutus, 2004 , p. 9) que o massacre ocorrera anos antes. 
16 "O dinheiro náo é o nervo da guerra". A mesma passagem é reproduzida por Harrington (1977, vol. 2, p. 690).

17 Em um escrito Leveller, de 1646, Richard Overton e William Walwyn (1998, p. 43) afirmam que a máxima divide et impera é de Maquiavel e é aplicada pela aristocracia contra o povo, numa defesa deste contra aquela. Tal afirmação também é feita por Sidney (1996, p. 147).

18 A importância de Gentillet no maquiavelismo é extremamente rica para que seja sumarizada. Marcamos apenas que ele esteve longe de conseguir uma repercussão inglesa como a da França. Seu livro foi publicado, em inglês, em 1602 (Praz, 1930, p. 8).

19 Armitage (1995, p. 207) destaca o contato político e profissional de Milton com Nedham à frente das publicaçōes oficiais do governo republicano entre 1652 e 1653, e afirma que isso corrobora com os temas maquiavelianos contidos em sua obra.

20 Lembre-se de que entre uma publicação e outra foi traduzido o Anti-Maquiavel, de Innocent Gentillet.

21 Não há evidências satisfatórias que liguem o adjetivo "político" do maquiavelismo ao uso que Bodin fizera do termo após a Noite de Sáo Bartolomeu, mas tal hipótese não parece improvável dada a proximidade com a qual ambos eram lidos.

22 Pocock (2003), Strauss (1953, p. 162) e Tuck (1979, p. 40), por diferentes caminhos, argumentam sobre a incompatibilidade de fundo teórico entre a dimensão republicana do humanismo cívico e de Maquiavel com o jusnaturalismo, alardeada nesse período.

\section{BIBLIOGRAFIA}

ALBERTINI, Rudolf Von. (1995), Firenze: dalla repubblica al principato: storia e coscienza politica. Trad. Cesare Cristofolini. Turim, Einaudi. ANGLO, Sydney. (2005), Machiavelli: the first century. Oxford, Oxford University Press.

ARIENZO, Alessandro. (2009), "Machiavelli e machiavellismo tra restaurazione Stuart e governo Orange", in A. Arienzo e G. Boreli (orgs.), Anglo americam face of Machiavelli: Machiavelli e Machiavellimo nella cultura anglo-americana (secoli XVI-XX), Monza, Polimetrica.

ARMITAGE, David. (1995), "John Milton: poet against empire”, in D. Armitage (org.), Milton and Republicanism, Cambridge (MA), Cambridge University Press.

BACON, Francis. (1955), Select writings of Francis Bacon. Nova York, The Modern Library.

BACON, Francis. (1998), The history of Reign of King Henry VII and selected works. Cambridge (MA), Cambridge University Press.

BARDUCCI, Marco. (2009), "Machiavelli nella cultura politica inglese (1648-1652): Marchamont Nedham e Antony Ascham”, in A. Arienzo e G. Boreli (orgs.), Anglo americam face of Machiavelli: Machiavelli e Machiavellimo nella cultura anglo-americana (secoli XVI$-X X)$, Monza, Polimetrica.

BARDUCCI, Marco. (2013), "Order, conflict and liberty: Machiavellianism in English political thought", in A. Arienzo e A. Petrina (orgs.), $M a$ chiavellian encounters in Tudor and Stuart England: literary and political influence from the Reformation to the Restoration. Nova York, Ashgate.

BIGNOTTO, Newton. (no prelo), "Maquiavel e seus primeiros leitores", in F. M. Pinto e F. Benevenuto (orgs.), Filosofia, politica e cosmologia: ensaios sobre o Renascimento, Santo André (SP), Editora UFABC.

BRUCIOLI, Antonio. (1526), Dialogi della morale philosophia. Veneza, Gregorio di Gregori.

BRUTUS, Stephanus Junius. (2003), Vindiciae, contra tyrannos: or concerning the legitimate power of a prince over the people, and of the people over a prince. Trad. George Garnett. Cambridge, Cambridge University Press.

BURKE, Peter. (1991), "Tacitism, scepticism, and reason of state", in J. H. Burns (org.), The Cambridge history of the political thought, 1450-1700, Cambridge (MA), Cambridge University Press.

CAMOS, Rosanna Gorris. (2008), "Dans le labyrinthe de Gohory: lecteur et traducteur de Machiavel”. Laboratoire Italien, 8: 195-229

DIONISOTTI, Carlo. (1980), Machiavellerie: storia e fortuna di Machiavelli. Turim, Einaudi.

DONALDSON, Peter S. (1988), Machiavelli and the mistery of State. Cambridge (MA), Cambridge University Press.

FILMER, Robert. (1991), Patriarcha and other writings. Cambridge (MA), Cambridge University Press. 
FIRPO, Luigi. (1970), "Le origini dell'anti-machiavellismo". Il Pensiero Politico, 2 (3): 337-367.

FONTANA, Benedetto. (2013), "Capax imperii: Tacitus and the politics of Machiavelli". Storia del pensiero politico, 2 (2): 207-232

FOXLEY, Rachel. (2013), "Marchamont Nedham and Mystery of State", in G. Mahlberg e D. Wiemann (orgs.), European contexts for English republicanism, Burlington, Ashgate.

GENTILI, Alberico. (1924), De legationibus libri tres. Trad. Gordon L. Laing. Nova York, Oxford University Press.

GILBERT, Felix. (2012), Machiavelli e Guicciardini: pensiero politico e storiografia a Firenze nel Cinquecento. Trad. Franco Salvatorelli. 2. ed. Turim, Einaudi.

GUICCIARDINI, Francesco. (1983), Opere. Turim, Einaudi, 2 vols.

HARRINGTON, James. (1977), The political works of James Harrington. Cambridge (MA), Cambridge University Press, 2 vols.

HÖPFL, Harro. (2004), Jesuit political thought: the society of Jesus and the State, 1540-1640. Cambridge (MA), Cambridge University Press.

KAHN, Victoria. (1994), Machiavellian rhetoric: from counter-reformation to Milton. Princeton (NJ), Princeton University Press.

LEVETT, John. (1937), [Prefácios às edições dos Discorsi de 1599 e outra sem data publicados em Londres], in N. Orsini, Studdi sul rinascimento italiano in Inghilterra, Florença, Sanzoni. Appendice I.

MACHIAVELLI, Niccolò. (1540), Discorsi di Nicolo Machiauegli cittadino \& secretario fiorentino, sopra la deca di Tito Liuio. Veneza, Comin de Trino.

MACHIAVELLI, Niccolò. (1550), Discorsi di Nicolo Machiauelli fiorentino, sopra la prima deca di Tito Liuio. Veneza, Gabriel Giolito de Ferrari e Fratelli.

MACHIAVELLI, Niccolò. (1584), I discorsi di Nicolo Machiauelli, sopra la prima deca di Tito Liuio. Nuouellamente emmendanti \& con somma cura ristampati. Palermo [Londres], Antoniello degli Antonielli [John Wolfe].

MACHIAVELLI, Niccolò. (1630), De’ Discorsi Politici e Militari Libri Tre, Scelti fra grauissimi
Scritori da Amadio Niecollvcci: Toscano. Veneza, Marco Ginammi.

MACHIAVELLI, Niccolò. (1680), The works of the famous Nicholas Machiavel citizen and secretary of Florence. Trad. Henry Neville. Londres, Henry Neville.

MACHIAVELLI, Niccolò. (1997), Opere. Turim, Einaudi. 3 vols.

MALOY, Jason. (2008), "Puritan Machiavellism and Anglo-American democracy in the seventeenth century". Disponível em citation. allacademic.com/meta/p277947_index.html, consultado em 20/12/2013.

MELAMED, Abraham. (1983), "English travelers and Venetian Jewish scholars: the case of Simone Luzzatto and James Harrington", in G. Cozzi (org.), Gli ebrei e Venezia: secoli XIV-XVIII. Veneza, Comunità.

NEDHAM, Marchamont. (1969), The case of the commonwealth of England, stated. Charlottesville, Virginia University Press.

NEDHAM, Marchamont. (2003), The excellencie of a free-State or, the right constitution of a commonwealth. Indianapolis, Liberty Fund.

NEVILLE, Henry. (1969), "Plato Redivivus or, a dialogue concerning government", in C. Robbins (org.). Two English republican tracts, Cambridge (MA), Cambridge University Press.

NEVILLE, Henry. (1680), "The publisher to the reader", in N. Machiavel, The works of the famous Nicholas Machiavel citizen and secretary of Florence, trad. Henry Neville, Londres, Henry Neville.

ORSINI, Napoleone. (1936), Bacone e Machiavelli. Gênova, Orfini.

ORSINI, Napoleone. (1937), Studii sul rinascimento italiano in Inghilterra. Florença, Sanzoni.

OVERTON, Richard \& WALWYN, William. (1998), "A remonstrance of many thousand citizens", in A. Sharp (org.), The English levelers, Cambridge (MA), Cambridge University Press.

PETRINA, Alessandra. (2009a), "Machiavelli beyond the channel: the first English translation of The Prince", in A. Arienzo e G. Boreli (orgs.), Anglo-American face of Machiavelli: Machiavelli e Machiavellismi nella cultura anglo-americana (secoli XVI-XX), Monza, Polimetrica. 
PETRINA, Alessandra. (2009b), Machiavelli in the British Isles: two early modern translations of The Prince. Farnham, Ashgate.

PETRINA, Alessandra. (2010), "A Florentine prince in queen Elizabeth's court", in R. del Po (org.), The first translations of Machiavelli's Prince, Nova York, Rodopi.

POCOCK, J. G. A. (2003), The Machiavellian moment: Florentine political thought and the Atlantic republican tradition. 2. ed. Princeton (NJ), Princeton University Press.

PRAZ, Mario. (1930), Machiavelli e gli inglesi dell'epoca elisabetiana. Florença, Vallechi.

PROCACCI, Giuliano. (1965), Studi sulla fortuna del Machiavelli. Roma, Istituto Teorico Italiano per l'Età Moderna.

PROCACCI, Giuliano. (1995), Machiavelli nella cultura europea dell'età moderna. Roma, Laterza.

RAAB, Felix. (1965), The English face of Machiavelli: a changing interpretation 1500-1700. Toronto, University of Toronto Press.

RAHE, Paul. (2008), Against throne and altar: Machiavelli and political theory under the English republic. Cambridge (MA), Cambridge University Press.

SIDNEY, Algernon. (1990), Discourses concerning government. Indianapolis, Liberty Fund.

SIDNEY, Algernon. (1996), Court Maxims. Cambridge (MA), Cambridge University Press.

SKINNER, Quentin. (1998), Liberty before liberalism. Cambridge (MA), Cambridge University Press.

SKINNER, Quentin. (2002), Visions of politics II: renaissance virtues. Cambridge (MA), Cambridge University Press.

SMITH, Margaret M. B. (2006), "The philosophy of liberty: Locke's Machiavellian teaching", in P. Rahe (org.), Machiavelli's liberal republican legacy, Cambridge (MA), Cambridge University Press.

SULLIVAN, Vickie. (2004), Machiavelli, Hobbes and the formation of the liberal republicanism in England. Cambridge (MA), Cambridge University Press.

STRAUSS, Leo. (1953), Natural right and history. Chicago, Chicago University Press.
TACITUS. (1937), The annals. Trad. John Jackson. Cambridge (MA), Harvard University Press.

TOFFANIN, Giuseppe. (1921), Machiavelli e il "Tacitismo": la "Politica Storica" al tempo della controriforma. Pádua, Angelo Draghi.

TUCK, Richard. (1979), Natural rights theories: their origin and development. Cambridge (MA), Cambridge University Press.

VILLARI, Pasquale. (1927), Machiavelli e $i$ suoi tempi. Milão, Editore-Libraio della Rel Casa, 2 vols.

WOLFE, John. (1584), "Lo stampatore al lettore", in N. Machiavelli, I discorsi di Nicolo Machiauelli, sopra la prima deca di Tito Liuio. Nuouellamente emmendanti \& con somma cura ristampati. Palermo [Londres], Antoniello degli Antonielli [John Wolfe].

ZUCKERT, Michael. (1994), Natural rights and the new republicanism. Princeton (NJ), Princeton University Press. 


\section{A PECULIARIDADE DO MAQUIAVELISMO INGLÊS: DAS ORIGENS AO SÉCULO XVII}

\section{Luís Falcão}

Palavras-chave: Maquiavel; Maquiavelismo; Inglaterra; Republicanismo; Discursos sobre a primeira década de Tito Lívio.

O presente artigo visa explorar as especificidades da recepção de Maquiavel na Inglaterra em seus momentos iniciais. A partir das fontes originais, aborda as ediçôes dos séculos XVI e XVII de "Discursos sobre a primeira década de Tito Lívio", com seus prefácios e apresentaçôes, em paralelo com a divulgação das ideias. Argumenta que, diferentemente do que ocorreu no continente, a chegada elogiosa e pioneira dos Discorsi, juntamente com o ambiente político do país, propiciou um Maquiavel defensor da liberdade e do bom governo. Apesar de extensa bibliografia sobre o tema, ainda não se concedeu a devida atenção a esse período, sobretudo em seu cotejo com a fama de Maquiavel na própria Itália e a disseminação editorial. Não obstante as críticas religiosas, suas obras sofreriam mais com a consolidaçáo do direito natural em meados do século XVII e, com ele, o maquiavelismo inglês entraria em decadência.

\section{THE PECULIARITY OF ENGLISH MACHIAVELLIANISM: FROM ITS ORIGINS TO THE SEVENTEENTH CENTURY}

Luís Falcão

Keywords: Machiavelli; Machiavellianism; England; Republicanism; Discourses on the first decade of Titus Livius.

This paper explores the specificities of the early stages of Machiavelli's reception in England. Studying original sources pertaining to said reception, it deals with the XVI and XVII century editions of the Discourses on the first decade of Titus Livius, with their prefaces and presentations considered in parallel with the dissemination of his ideas. It argues that, unlike the events in the continental Europe at that time, the commendable and pioneering arrival of the Discorsi, together with the political environment of the country, provided a view of Machiavelli as a defender of freedom and good government. Despite extensive bibliography on the subject, this period has not yet been given due attention - especially regarding its comparison of Machiavelli's fame in Italy itself to the editorial dissemination of his works. Religious criticism notwithstanding, his works suffered more due to the natural law theories during the middle of XVII century, and thus English Machiavellianism decayed.

\section{LA PARTICULARITÉ DE MACHIAVÉLISME ANGLAIS : DES ORIGINES AU XVIIÈME SIÈCLE}

\section{Luís Falcão}

Mots-clés: Machiavel; Machiavélisme; Angleterre; Républicanisme; Discours sur la première décennie de Tite-Live.

Cet article explore les spécificités de l'accueil de Machiavel à ses débuts, en Angleterre. À partir de sources originales, l'article aborde les éditions des XVIème et XVIIème siècles, avec ses préfaces et ses introductions, parallèlement à la diffusion d'idées. Nous considérons que, contrairement à ce qui s'est produit sur le continent, l'arrivée élogieuse et pionnière desDiscorsi, associée à l'environnement politique du pays, a favorisé un Machiavel défenseur de la liberté et du bon gouvernement. Malgré une importante bibliographie sur le sujet, cette période n'a pas joui de l'attention méritée, en particulier par rapport à sa comparaison avec la notoriété de Machiavel en Italie et sa diffusionéditoriale. Malgré les critiques religieuses, ses œuvres ont souffert davantage avec la consolidation du droit naturel au milieu du XVIIème siècle et, grâce àlui, le machiavélisme anglais entrera en décadence. 


\section{ERRATA}

RBCS vol.33 no 97/2018

DOI: $10.1590 / 339700 / 2018 \mathrm{ER}$

E-location: e339700ER

- Nos artigos: "O comitê de articulação federativa no governo Lula: os percalços da cooperação territorial"; "Marcuse crítico de Weber: a política no capitalismo tardio"; "Representação política: a virada construtivista e o paradoxo entre criação e autonomia"; "O pequeno investidor na bolsa brasileira: ascensão e queda de um agente econômico"; "Ciências humanas e neurociências: um confronto crítico a partir de um contexto educacional"; "A peculiaridade do maquiavelismo inglês: das origens ao século XVII"; "Internacionalização de micro, pequenas e médias empresas inovadoras no Brasil: desafios do novo paradigma de desenvolvimento"; "A luta pelo reconhecimento e o paradigma da dádiva: uma proposta de articulação teórica" e "Determinantes individuais e de contexto da simpatia partidária na América Latina", assim como nas resenhas: "Um acerto de contas com o judiciário argentino", "A imprevisibilidade democrática" e "Idle No More: sobre a mobilização indígena no Canadá", publicados na Revista Brasileira de Ciências Sociais, 2018, volume 33, número 97, cujos e-locations são respectivamente: e339703, e339704, e339705, e339710, e339702, e339706, e339708, e339709, e339711, e339715, e339716 e e339717, os prefixos do DOI estáo incorretos.

Onde se lia: "10.590"

Leia-se: "10.1590". 